\title{
An Assessment in SpondyloArthritis international Society (ASAS)-endorsed definition of clinically important worsening in axial Spondyloarthritis based on the ASDAS
}

Anna MOLTO ${ }^{1,2}$, Laure GOSSEC ${ }^{3,4}$, Bhowmik MEGHNATHI ${ }^{1}$, Robert LANDEWE ${ }^{5}$, Désirée van der HEIJDE ${ }^{6}$, Pamir ATAGUNDUZ ${ }^{7}$ Bassel EL ZORKANY ${ }^{8}$, Nurullah AKKOC ${ }^{9}$, Uta KILTZ ${ }^{10}$, Jieruo $\mathrm{GU}^{11}$, James CHENG-CHUNG WEI ${ }^{12}$, and Maxime DOUGADOS ${ }^{1,2}$ on behalf of the ASAS-FLARE study group.

1: Paris Descartes University, Medicine Faculty; APHP, Rheumatology B Department, Cochin Hospital, Paris France

2: Inserm Unit INSERM (U1153): Clinical Epidemiology and Biostatistics; PRES Sorbonne Paris-Cité, Paris France

3: Sorbonne Universités, UPMC Univ Paris 06; AP-HP, Pitié Salpêtrière Hospital, Department of rheumatology, Paris, France

4: Institut Pierre Louis d'Epidémiologie et de Santé Publique, GRC-UPMC 08 (EEMOIS), Paris, France

5: Department of Clinical Immunology \& Rheumatology, Amsterdam Rheumatology Center, Amsterdam and Zuyderland Medical Center, Heerlen, The Netherlands

6: Department of Rheumatology, Leiden University Medical Centre, Leiden, The Netherlands

7: Department of Rheumatology, Faculty of Medicine, Marmara University, Istanbul, Turkey.

8: Rheumatology Department, Cairo University, Cairo, Egypt

9: Dokuz Eylul university school of medicine, internal medicine/division of rheumatology, Izmir, 35340, Turkey.

10: Rheumazentrum Ruhrgebiet, Herne, Germany.

11: Department of Rheumatology and Immunology, The Third Affiliated Hospital of Sun Yat-Sen University, Guangzhou, Guangdong, P.R. China.

12: Division of Allergy, Immunology and Rheumatology, Chung Shan Medical University Hospital; Institute of Medicine, Chung Shan Medical University; Graduate Institute of Integrated Medicine, China Medical University, Taichung, Taiwan.

WORD COUNT: 1523 
Corresponding author:

Anna MOLTO, MD, PhD

27 rue du Faubourg Saint Jacques, 75014, Paris, FRANCE

$0033(0) 158412617 / 0033(0) 677327104$

anna.molto@aphp.fr 
Members ASAS-FLARE study group:

A MOLTO, L GOSSEC, B MEGHNATHI, RLANDEWE, D van der HEIJDE, P ATAGUNDUZ, B EL ZORKANY, N AKKOC, U KILTZ, J GU, J CHENG-CHUNG WEI, M DOUGADOS,S PANDYA, V NAVARRO, I GAYDUKOVA, P GEHER, A SPOORENBERG, S AYDIN, F PIMENTEL, M KISHIMOTO, F van GALLEN, E COLLANTES-ESTEVEZ, R SCHIOTIS, H MARZO-ORTEGA, B O'SHEA, C RAMOS-REMUS, and M MAGREY, 
ABSTRACT:

Introduction: In a previous phase, 12 draft-definitions for clinically important worsening in axial spondyloarthritis (axSpA) were selected, of which 3 were based on absolute changes in ASDAS-CRP (ASDAS). The objective here was to select the best cut-off for the ASDAS for clinically important worsening in axSpA for use in clinical trials and observational studies.

Methods: An international longitudinal prospective study evaluating stable axSpA patients was conducted. Data necessary to calculate ASDAS were collected at 2 consecutive visits (spaced 7 days to 6 months). Sensitivity and specificity of the 3 cut-offs for change in ASDAS were tested against the patient's subjective assessment of worsening as the external standard (i.e., the patient reporting that he had worsened and felt a need for treatment intensification). Final selection was made by a consensus and voting procedure among ASAS members.

Results: In total, 1169 axSpA patients were analysed: $64.8 \%$ were males and had a mean age of 41.7 (SD 12.4) years. At the second visit, 127 (10.9\%) patients judged their situation as worsened.

Sensitivity and specificity for an increase of at least $0.6,0.9$ and 1.1 ASDAS points to detect patient-reported worsening were $0.55(\mathrm{Se})$ and 0.91 (Sp), 0.38 (Se) and $0.96(\mathrm{Sp})$, and 0.33 (Se) and 0.98 (Sp) respectively. The ASAS consensus was to define clinically important worsening as an increase in ASDAS of at least 0.9 points.

Conclusion: This data-driven ASAS consensus process resulted in an ASDAS-based cut-off value defining clinically important worsening in axSpA for use in trials. 
The course of axial spondyloarthritis (axSpA) is characterized by periods of flares (clinical worsening) and remission. Current definitions for clinical disease worsening in axSpA are very heterogeneous across clinical trials. This is a particular problem in discontinuation trials, which aim to discontinue the treatment in patients in remission and only resume the treatment in case of disease worsening. The absence of a consensual definition for clinically important worsening of disease activity in axSpA jeopardises the interpretation of - and comparison across - trials.

The Assessment of SpondyloArthritis international Society (ASAS) is a world-wide independent consortium of experts in spondyloarthritis $(\mathrm{SpA})$, which has developed and validated most of the criteria and outcome measures currently used in SpA clinical trials. This includes the Ankylosing Spondylitis Disease Activity Score (ASDAS) as a disease activity measure with validated cut-offs for various disease activity states and improvements.[1,2] ASAS has decided to define also a cut-off for clinically important worsening in axSpA. The first two steps of this process have been already reported [3]: first, a systematic literature review of definitions of 'disease worsening' in published randomized controlled trials in axSpA was performed, yielding 38 studies using some definition of 'disease worsening' and 27 different definitions, most frequently based on Bath Ankylosing Spondylitis Disease Activity Index (BASDAI) [4] or pain. Second, a vignette exercise was performed involving 121 ASAS experts and 140 scenarios of disease worsening: each scenario included a change in one of the outcomes (pain, BASDAI, BASDAI plus C-reactive protein (CRP) or ASDAS [1]). Each ASAS expert judged for each of 46 randomly developed scenarios if the scenario was compatible with disease worsening (yes/no). Receiver-operating characteristic analyses were applied to derive optimal cutoff values for pain $(N=3)$, BASDAI $(N=5)$ and $\operatorname{ASDAS}(N=4)$, leading to 12 preliminary definitions of 'worsening' in axSpA, based on widely used indices. These results were presented at the 2015 annual ASAS workshop. It was felt that, based on the currently available data, it was impossible to prioritize one of the 12 scenarios, and that arguments for a further reduction of the number of scenarios should come from data observed in clinical practice.

Thus, we conducted a clinical observational study aiming to evaluate the psychometric properties of the $12 \mathrm{draft}$ definitions of clinically important worsening in axial SpA. The results of the study were presented at the 2017 annual ASAS workshop and a consensus and voting procedure has resulted in a final choice. 


\section{METHODS}

Study design: An international (including 20 countries), longitudinal (2 visits: with an interval between 1 week - 6 months), observational study was conducted in 2016 . The study was conducted in agreement with good clinical practice, approved by ethics committees (at the local level) and a written informed consent was obtained from all patients. Patients: axSpA patients with stable disease (no need for a treatment change) according to the rheumatologist. Data collected: Demographics and disease characteristics were collected at baseline, and data on disease activity (including CRP) were collected at both visits. Clinical worsening was defined at the follow-up visit by the patient answering the following question ("Think about all the ways your spondyloarthritis has affected you during the last 48 hours. Compared to the last visit how did you feel during the last 48 hours? Improved/No change/Worse"). When patients answered "worse" they were asked if they considered treatment intensification was necessary (yes/no). Patient's perception of worsening was defined as the patient reporting that he/she had worsened and that he/she felt there was a need for treatment intensification.

\section{Analysis:}

Pain:_question 2 of the BASDAI (back Pain) was used. Three pain-based cut-offs were proposed based on the previous exercise [3] (see Table 2).

BASDAI: BASDAI was calculated as follows: (Fatigue + Back Pain+ Peripheral Pain + Entheseal Pain + ((Level of Morning Stiffness + Duration of Morning Stiffness)/2))/5 [4].

Five BASDAI cut-offs were proposed [3] (Table 2).

ASDAS:_the ASDAS formula with CRP was used (i.e. ASDAS $=0.12 \times$ Back Pain $+0.06 \times$ Duration of Morning Stiffness + $0.11 \times$ Patient Global + $0.07 \times$ Peripheral Pain/Swelling + $0.58 \times \operatorname{Ln}(C R P+1))$. When the CRP level was below the limit of detection or $<2 \mathrm{mg} / \mathrm{IL}$, the constant value of $2 \mathrm{mg} / \mathrm{L}$ was used to calculate the ASDAS score as recommended [2].

Four ASDAS-based cut-offs were proposed based on the previous exercise, with only 3 absolute changes:[3] an increase in ASDAS of at least 0.6; an increase in ASDAS of at least 0.6 points and a final ASDAS $\geq 1.3$; an increase in ASDAS of at least 0.9 points; and an increase in ASDAS of at least 1.1 points;

Sensitivity (that is: the likelihood to be considered as 'worse' by the scenario among all patients considering themselves worse) and specificity (that is: the likelihood to be considered as 'not worse' by the scenario, among all patients not considering themselves worse) were tested. 
The results of this analysis were presented at the 2017 annual ASAS workshop together with the previous results from the 2015 consensus (based on the physician's perspective), followed by a consensus and voting procedure by the ASAS members.

\section{RESULTS}

The flow chart of the study is summarized in Fig 1: among the 1639 patients included, 1169 patients provided complete data. Patients were predominantly male $(64.8 \%)$ and had a mean (SD) age of 41.7 (12.4) years. History of radiographic sacroiliitis, MRI sacroiliitis and HLAB27 positivity were reported in 944 (80.8\%), 471 (40.6\%) and 807 (69.0\%) patients, respectively. Baseline means (SD) for BASDAI (0-10), ASDAS and CRP were 3.1 (2.3), 2.3 (1.0) $8.4 \mathrm{mg} / \mathrm{L}(14.5)$ respectively (Table 1).

The mean interval between both visits was 91.2 (SD 51.0) days, and at follow-up visit, means (SD) for BASDAI, ASDAS and CRP were 2.9 (2.2), 2.1 (1.0) and 7.4 (11.8) mg/L.

A total of $590(50.5 \%), 388(33.2 \%)$ and 191 (16.3\%) patients considered their condition as improved, not changed and worsened, respectively. Among the 191 patients reporting a worsening, 127 (66.5\%) found that their status required treatment intensification. Thus, $127(10.8 \%)$ patients fulfilled the external standard definition of clinical worsening according to the patient's perception. Table 2 summarizes these performances, along with those from the physician case-vignette exercise in which the external standard was the physician's perception[3]. The 3 cut-offs of ASDAS change (i.e. increase of $0.6,0.9$ and 1.1 points) yielded a sensitivity of $0.55,0.38$ and 0.33 , respectively, and a specificity of 0.91 , 0.96 and 0.98 , respectively.

In January 2017, the ASAS membership discussed the data at length. Almost all ASAS members were in favour of selecting a cut-off based on the data (67 votes in favor vs. 1 against). All members were against defining a cut-off based on pain. No consensus was reached for a BASDAI-based definition due to limited performance of all cut-offs, and $50 \%$ of members voted against deciding a cut-off for BASDAI.

Regarding ASDAS cut-offs, the majority chose the cut-off of at least 0.9 point increase as the definition for clinically important worsening ( 6 votes in favor of 0.6 ; 64 votes in favor of 0.9 and no votes in favor of $1.1 \mathrm{n}=0$ (6 abstained)). Thus, an increase of at least 0.9 points was retained as the ASAS-definition for clinically important worsening in axSpA, to be used in studies. 


\section{DISCUSSION}

This three-step data-driven ASAS consensus process has allowed proposing an ASDASbased cut-off value defining clinically important worsening in axSpA. The final definition is the result of a comprehensive process involving a systematic literature review, a casevignette exercise using the physician's perspective as external standard[3], a real-life study on worsening with the patient's perspective as external standard and a consensus and voting procedure among SpA experts.

Several cut-offs have already been defined for ASDAS, but only for either improvement changes or status.[6] It is worth noting that the minimum clinically important improvement of ASDAS is defined as a decrease of at least 1.1 points, which is a greater change than the change required for the predicate of clinically important worsening. This seemingly paradoxical finding is not unusual: in other disciplines MCID-thresholds for deterioration have often been reported to be lower than for improvement. $[7,8]$ A potential limitation of this study was the discrepancy between patient's and physician's perception in terms of sensitivity: indeed, when tested against patient's perception, cutoffs yielded much lower sensitivity values as compared with physician's perception. This is not surprising, as patients might report feeling worse already at much lower changes as compared to physicians, and such discrepancies have been grounded in the literature [9]. Secondly, the 0.9 ASDAS point increase definition had only moderate sensitivity (0.38) against the patient's perception, but excellent specificity against both patient's and physician's perception. This high level of specificity was considered more important than sensitivity since the definition will be used in the context of clinical trials. The definition for clinically important worsening will typically be used in a treatment-withdrawal trial: a SpA-patient will stop treatment if clinical remission has been achieved and will resume the treatment in case of 'true worsening'. A high specificity reduces the number of "falsepositive worsenings" and the subsequent (unnecessary) retreatment.

In summary, a definition for clinically important worsening in axSpA based on the ASDAS has been defined, validated and endorsed by ASAS. This definition should now be used in clinical trials and follow-up studies. 


\section{REFERENCES}

1 Lukas C, Landewé R, Sieper J, et al. Development of an ASAS-endorsed disease activity score (ASDAS) in patients with ankylosing spondylitis. Ann Rheum Dis 2009;68:18-24. doi:10.1136/ard.2008.094870

2 Machado P, Navarro-Compán V, Landewé R, et al. Calculating the ankylosing spondylitis disease activity score if the conventional c-reactive protein level is below the limit of detection or if high-sensitivity c-reactive protein is used: an analysis in the DESIR cohort. Arthritis Rheumatol Hoboken NJ 2015;67:408-13. doi:10.1002/art.38921

3 Gossec L, Portier A, Landewé R, et al. Preliminary definitions of 'flare' in axial spondyloarthritis, based on pain, BASDAI and ASDAS-CRP: an ASAS initiative. Ann Rheum Dis 2016;75:991-6. doi:10.1136/annrheumdis-2015-208593

$4 \quad$ Garrett S, Jenkinson T, Kennedy LG, et al. A new approach to defining disease status in ankylosing spondylitis: the Bath Ankylosing Spondylitis Disease Activity Index. J Rheumatol 1994;21:2286-91.

5 Tubach F, Ravaud P, Baron G, et al. Evaluation of clinically relevant states in patient reported outcomes in knee and hip osteoarthritis: the patient acceptable symptom state. Ann Rheum Dis 2005;64:34-7. doi:10.1136/ard.2004.023028

$6 \quad$ Machado P, Landewé R, Lie E, et al. Ankylosing Spondylitis Disease Activity Score (ASDAS): defining cut-off values for disease activity states and improvement scores. Ann Rheum Dis 2011;70:47-53. doi:10.1136/ard.2010.138594

7 Mannion AF, Porchet F, Kleinstück FS, et al. The quality of spine surgery from the patient's perspective: part 2. Minimal clinically important difference for improvement and deterioration as measured with the Core Outcome Measures Index. Eur Spine J Off Publ Eur Spine Soc Eur Spinal Deform Soc Eur Sect Cerv Spine Res Soc 2009;18 Suppl 3:374-9. doi:10.1007/s00586-009-0931-y

8 Horváth $\mathrm{K}$, Aschermann Z, Kovács M, et al. Minimal clinically important differences for the experiences of daily living parts of movement disorder societysponsored unified Parkinson's disease rating scale. Mov Disord Off J Mov Disord Soc 2017;32:789-93. doi:10.1002/mds.26960

9 Desthieux C, Molto A, Granger B, et al. Patient-physician discordance in global assessment in early spondyloarthritis and its change over time: the DESIR cohort. Ann Rheum Dis 2016;75:1661-6. doi:10.1136/annrheumdis-2015-208251 


\section{TABLES}

Table 1: Patients and disease characteristics ( $n=1169)$

\begin{tabular}{|c|c|}
\hline & $\begin{array}{c}\text { Total population } \\
\mathrm{N}=1169\end{array}$ \\
\hline Age (years) $(n=1168)^{*}$ & $42.0[32.0-50.0]$ \\
\hline Gender (Male) & $758(64.8 \%)$ \\
\hline HLA-B27 + (n=1137) & 807 (69.0\%) \\
\hline Disease duration (years) $(n=1163)$ & $10.0[5.0-18.0]$ \\
\hline Radiographic sacroiliitis ( $n=1164)$ & $944(80.8 \%)$ \\
\hline $\begin{aligned} & \text { MRI Sacroiliitis }(\mathrm{n}=1161) \\
& \text { - } \text { Positive } \\
& \text { - } \text { Negative } \\
& \text { - } \text { Never performed }\end{aligned}$ & $\begin{array}{c}471(40.6 \%) \\
102(8.8 \%) \\
588(50.6 \%)\end{array}$ \\
\hline Current NSAID intake $(n=1168)$ & $826(70.7 \%)$ \\
\hline Current biologic treatment $(n=1167)$ & $655(56.0 \%)$ \\
\hline CRP (mg/L) & $3.7[2.0-9.2]$ \\
\hline BASDAI (0-10) & $2.8[1.1-4.8]$ \\
\hline ASDAS & $2.1[1.4-3.0]$ \\
\hline
\end{tabular}

Footnote: * results are presented as median [Q1-Q3] or as number (\%);

Abbreviations : NSAID: non-steroidal anti-inflammatory drugs; CRP: C-reactive protein; BASDAI : Bath Ankylosing Spondylitis Disease activity Index; ASDAS: Ankylosing Spondylitis Disease Activity Score. 
Table 2: Performances of the cut-offs defining clinically important worsening

\begin{tabular}{|c|c|}
\hline $\begin{array}{c}\text { Prospective real-life } \\
\text { study } \\
\text { ( } \mathrm{N}=1169 \text { patients) } \\
\text { against the external } \\
\text { standard } \\
\text { 'patient-worsening' } \\
\text { (worsening: } \mathrm{N}=127 \text { ) }\end{array}$ & $\begin{array}{c}2015 \text { case -vignette } \\
\text { exercise }{ }^{1} \\
\text { ( } \mathrm{N}=1150 \text { physician } \\
\text { judgments) } \\
\text { against the external } \\
\text { standard } \\
\text { 'physician-worsening' } \\
\text { (worsening: } \mathrm{N}=591 \text { ) }\end{array}$ \\
\hline
\end{tabular}

Cut-off

Sensitivity Specificity Sensitivity Specificity

\begin{tabular}{|c|c|c|c|c|c|}
\hline \multirow{3}{*}{$\begin{array}{c}\text { Back Pain } \\
(0-10)\end{array}$} & $\Delta$ pain $\geq 2$ AND final pain $\geq 4$ & 0.42 & 0.91 & 0.99 & 0.30 \\
\hline & $\Delta$ pain $\geq 3$ & 0.29 & 0.95 & 0.95 & 0.69 \\
\hline & $\begin{array}{l}\text { If Back Pain value is } \geq 4 \text {, then } \Delta \text { pain } \geq 2 \\
\text { points, if else, } \Delta \text { pain } \geq 3 \text { points }\end{array}$ & 0.43 & 0.91 & 0.97 & 0.56 \\
\hline \multirow{5}{*}{$\begin{array}{c}\text { BASDAI } \\
(0-10)\end{array}$} & $\triangle$ BASDAI $\geq 2$ points & 0.31 & 0.96 & 0.99 & 0.40 \\
\hline & $\triangle$ BASDAI $\geq 2$ points AND final BASDAI $\geq 4$ & 0.24 & 0.98 & 0.99 & 0.32 \\
\hline & $\triangle \mathrm{BASDAI} \geq 3$ points & 0.17 & 0.99 & 0.92 & 0.70 \\
\hline & $\triangle$ BASDAI $\geq 3$ points AND final BASDAI $\geq 4$ & 0.16 & 0.99 & 0.94 & 0.63 \\
\hline & $\begin{array}{l}\text { If BASDAI value is } \geq 4 \text {, then } \Delta \text { BASDAI } \geq 2 \\
\text { points, if else, } \triangle \text { BASDAI } \geq 3 \text { points }\end{array}$ & 0.25 & 0.98 & 0.94 & 0.54 \\
\hline \multirow{4}{*}{ ASDAS } & $\triangle$ ASDAS $\geq 0.6$ & 0.55 & 0.91 & 0.97 & 0.65 \\
\hline & $\triangle$ ASDAS $\geq 0.9$ & 0.38 & 0.96 & 0.85 & 0.87 \\
\hline & $\triangle \mathrm{ASDAS} \geq 1.1$ & 0.33 & 0.98 & 0.60 & 0.94 \\
\hline & $\triangle$ ASDAS $\geq 0.6$ AND final ASDAS $\geq 1.3$ & 0.55 & 0.91 & 0.97 & 0.59 \\
\hline
\end{tabular}

1: Gossec L, et al. Preliminary definitions of 'flare' in axial spondyloarthritis, based on pain, BASDAl and ASDAS-CRP: an ASAS initiative. Ann Rheum Dis. 2016;75:991-6.

Footnote: ASDAS: Ankylosing Spondylitis Disease Activity Score-CRP. BASDAI: Bath Ankylosing Spondylitis Activity Index; 


\section{FIGURE LEGENDS}

Figure 1: Flow Chart of the Study.

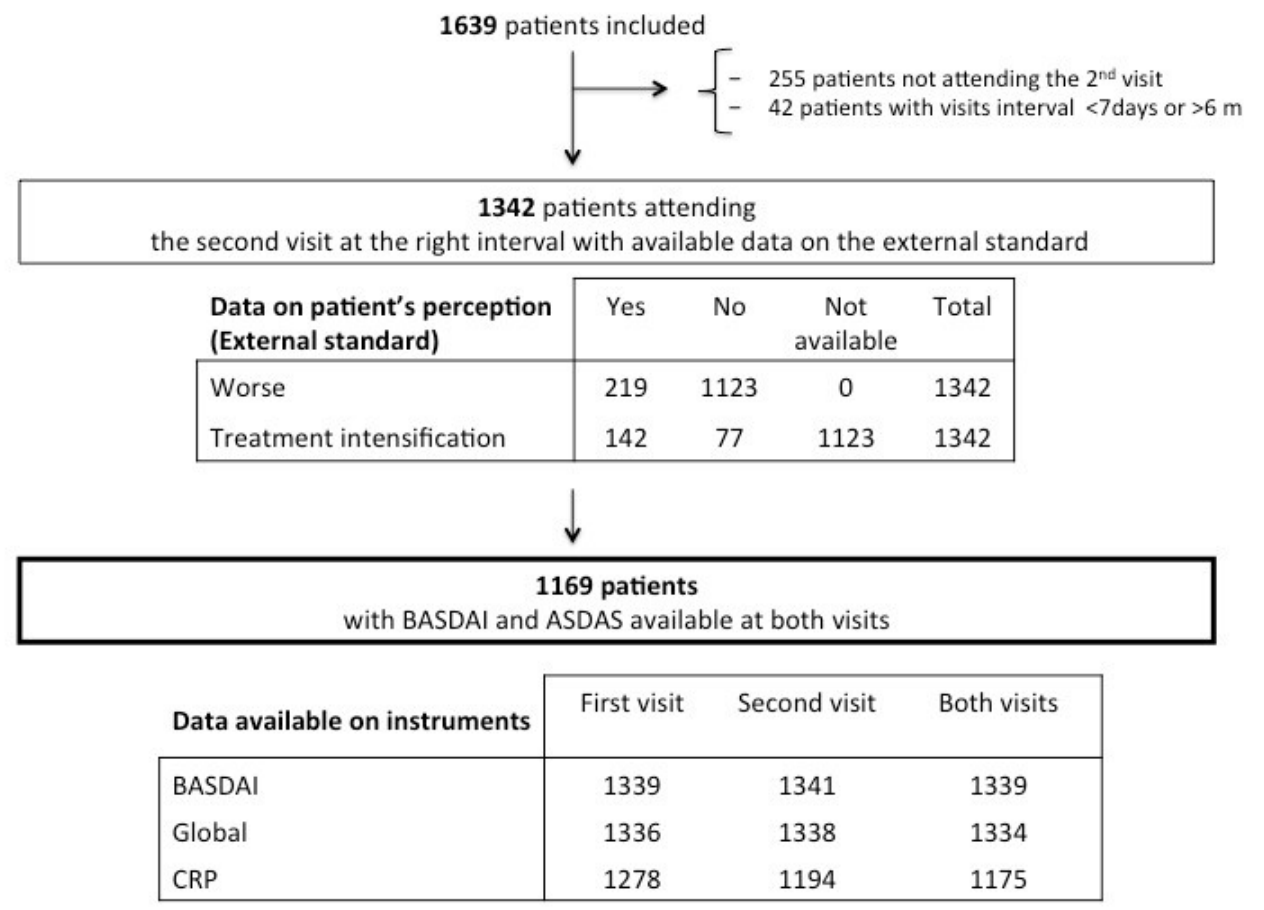

Footnote: BASDAI : Bath Ankylosing Spondylitis Disease Activity Index; CRP : C-reactive Protein;

ASDAS: Ankylosing Spondylitis Disease Activity Score - CRP 